\title{
A Method to Machine a Curved Tunnel with EDM
}

\author{
A. Goto*, K. Watanabe**, A. Takeuchi** \\ ( Received on September 17, 2001 ) \\ * Nagoya Works, Mitsubishi Electric Corp., Nagoya 461-8670, Japan \\ ** Toyota Motor Corp., Toyota 471-8574, Japan
}

\begin{abstract}
It is necessary for injection or die-cast manufacturers to improve quality of products and shorten the time to delivery. In this paper, a system to machine a curved tunnel into a workpiece is proposed. This system is composed of a curved electrode-drive part that has an electrode at the end of it and a guide to straighten the electrode-drive part. Machining test was done with the system and it was confirmed that a curved tunnel can be machined. With this technology, temperature adjustment will be precise and quality of injection products will be improved.
\end{abstract}

Key words: EDM, Curved hole, coolant

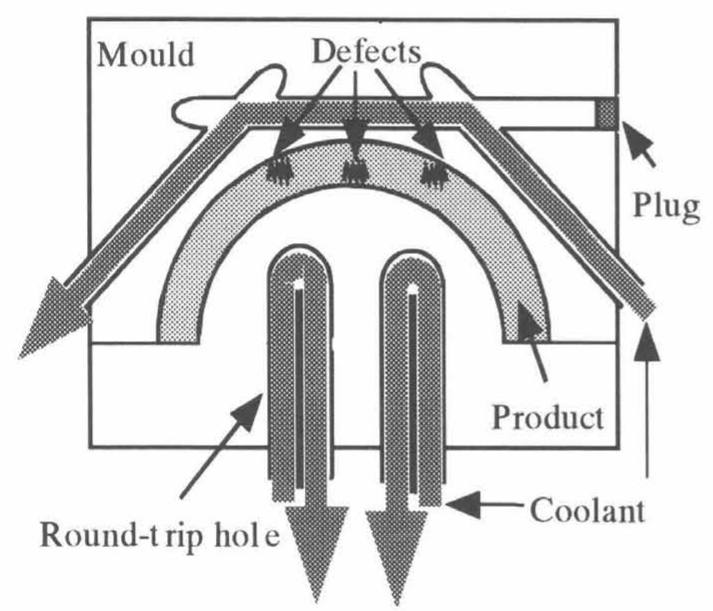

Figure 1 Example of coolant tunnel with straight holes

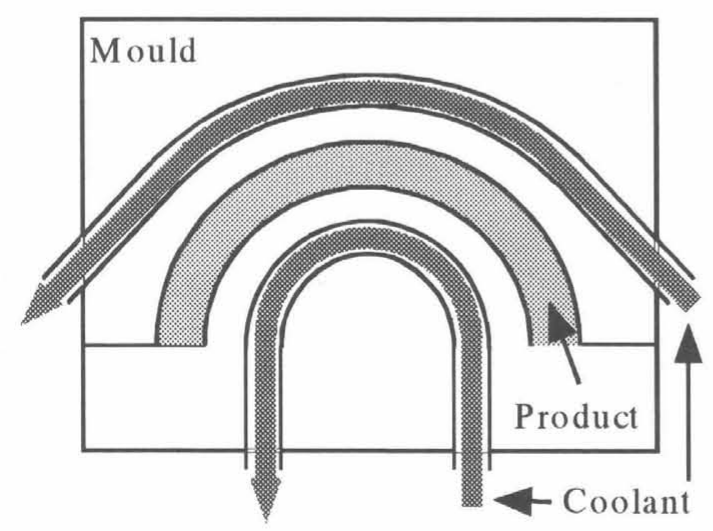

Figure 2 Example of curved tunnel

\section{INTRODUCTION}

It is necessary for injection or die-cast manufacturers to improve quality of products and shorten the time to delivery, and delivery time of dies or moulds are becoming shorter and shorter. But it is also necessary to improve injection technology to realize good quality of products. In this paper, a new method to make a curved tunnel into a workpiece is shown. With this technology, temperature control will be precise and quality of injection products will be improved.

Figure 1 is an example of a traditional coolant tunnel of an injection mold. Usually it is a combination of straight holes and likely to make defects to an injection product. So a new coolant tunnel as shown in figure 2 is necessary to improve quality of an injection product. In this paper a method to machine such an curved tunnel into a workpiece is proposed.

\section{HISTORY OF MOLE-EDM}

The first research of making a curved tunnel into a workpiece was made by Fukui et al. ${ }^{1) \sim 3)}$, and this report is also based on these reports.

It is ideal that curved tunnel can be machined to any direction, and authors made a electrode-drive system shown in figure 3 . This is a multi-joint system and each joint has a shape-memory-alloy coil as an actuator. This system has a problem that machining efficiency is quite low, because the electrode contacts the workpiece when joint is bent ${ }^{4), 5}$.

Including the above-mentioned problem there are some problems to be solved with machining of curved tunnels;

(1) Stability of machining 


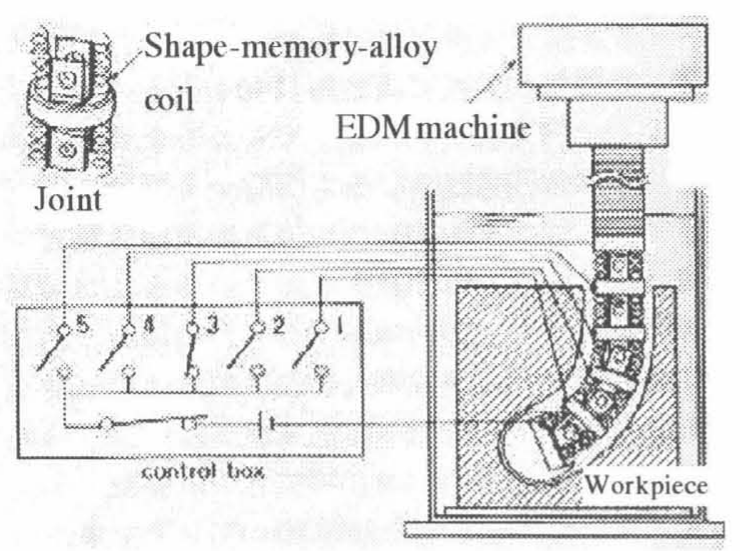

Figure 3 Structure of Mole-EDM system with shape-memory-alloy[4]

(2) Detection and control of machining position

(3) Machining accuracy

So in this report, a new method is proposed to resolve above-mentioned problems with a restriction of tunnel shape.

\section{STRUCTURE OF THE APPARATUS}

It is ideal that curved tunnel can be machined to any direction, but most cases are likely to be satisfied with a tunnel that has a straight part and following curved part. In this report, a machining system to machine such a tunnel is designed.

Structure of the apparatus is shown in figure 4 . The electrode is fixed to the coil spring which has a curvature at the top area of it. The coil spring is insulated from the electrode. Another end of the coil spring is fixed to the EDM machine's Z axis. The curvature of the apparatus is copied to a tunnel machined with it, and it can be adjusted by parts fixed to the coil spring ( figure 5 ).

The way of machining is explained with figure 6 . The electrode-drive part which has a curvature is inserted into the guide shown in figure 6 (a) to make it straight, and when straight part of the tunnel is dug, both the electrode-drive part and the guide are pushed into a workpiece simultaneously. And next, when the curved part of the tunnel is dug, as shown in figure 6 (b) and (c), the guide is fixed and the electrode-drive part ( coil spring) is driven into the workpiece. When the electrode-drive part is pushed out of the guide, it get back to the curved shape, and copies its curvature to the tunnel dug into a workpiece.

With this system, machining stability is quite good because the gap distance between the electrode and the workpiece is easily controlled by the feed and return of the electrode-drive part ( coil spring ).

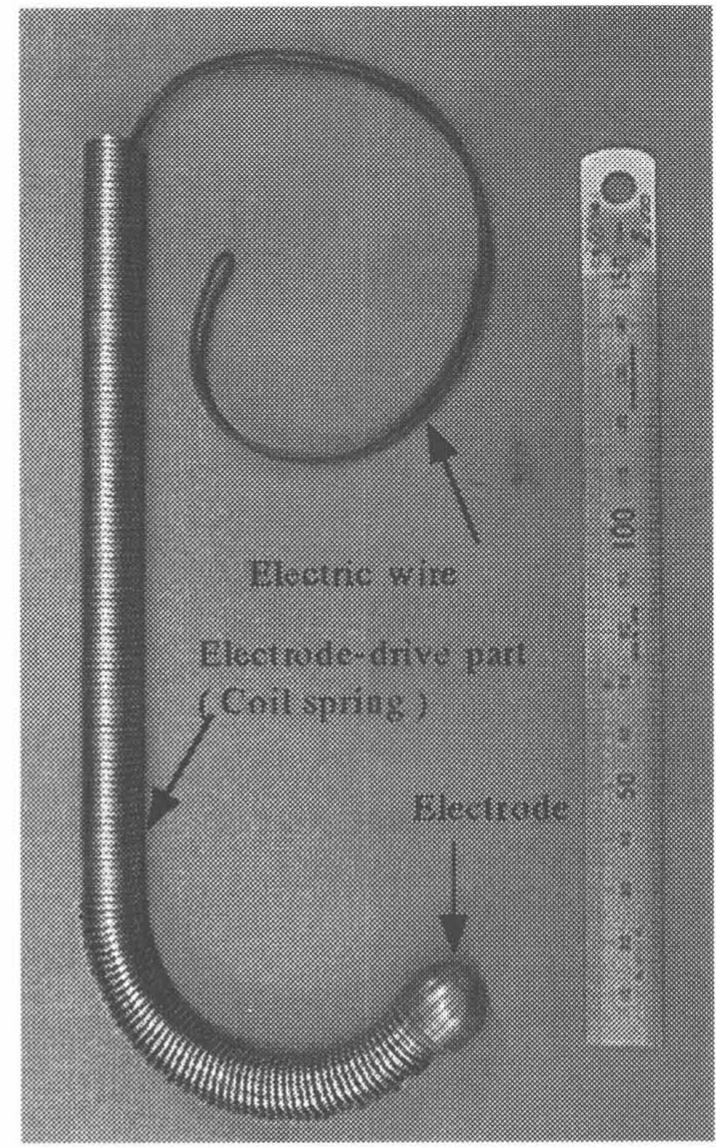

Figure 4 Structure of the system
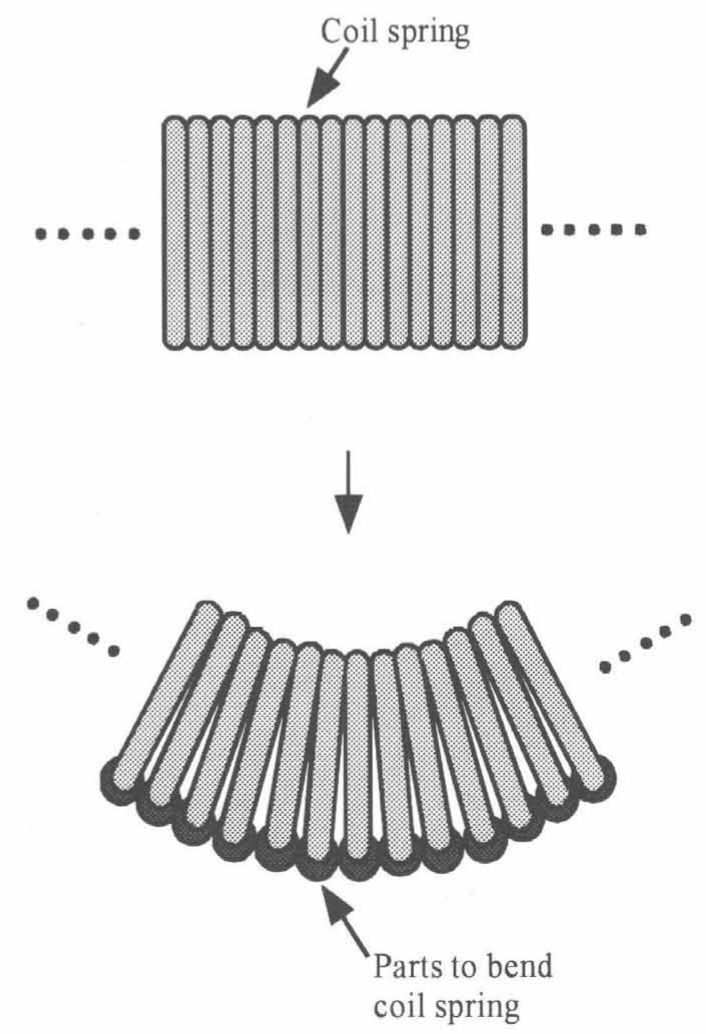

Figure 5 How to bend coil spring 


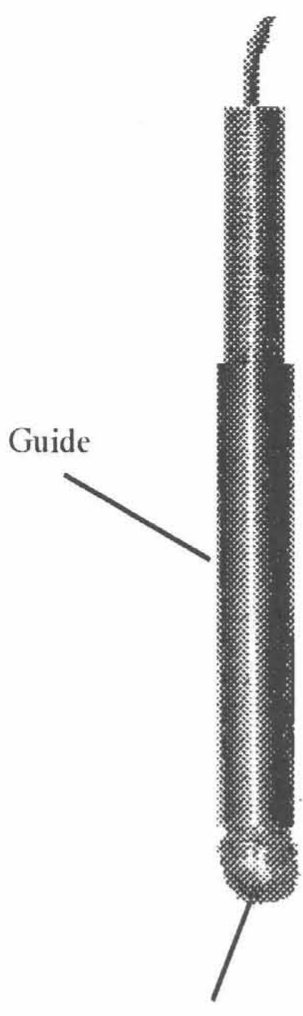

Electrode

(a)

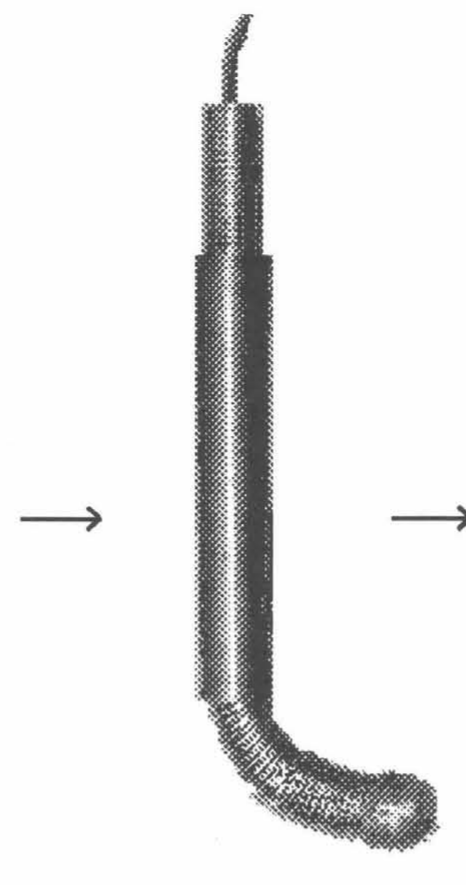

Eletrode-drive part which has a curvature

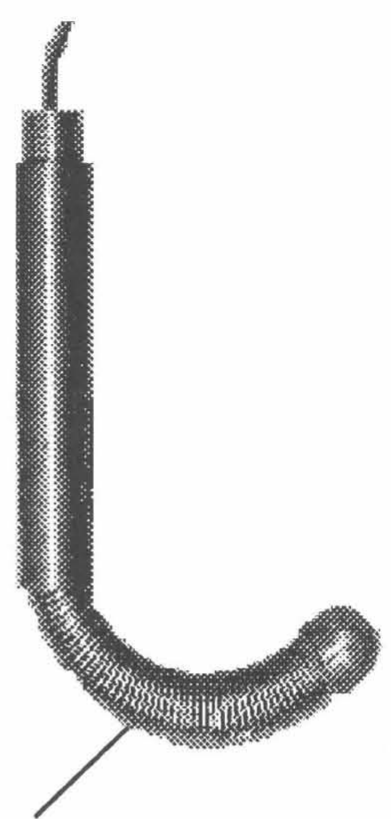

(c)

Figure 6 Movement of the system

As for machining accuracy, it is good to some degree when a coolant tunnel is machined with this system, because the electrode position can be roughly calculated by the curvature of the electrode-drive part and its feed. Though machining accuracy of this system depends on stiffness of the electrode-drive part, it is considerably improved compared with the precedents 3)4)5).

\section{MACHINING EXAMPLE}

Machining test was done with this system. Workpiece material was aluminum. Straight part of tunnel was machined with another solid electrode in order to make the experiment easier. Machining conditions for curved part are as follows;

\section{Electrical conditions}

Peak current ie $=25 \mathrm{~A}$

Pulse duration te $=128 \mu \mathrm{s}$

Pulse interval time to $=32 \mu \mathrm{s}$

Pre-machined straight hole

Electrode diameter : $20 \mathrm{~mm}$

Depth : $30 \mathrm{~mm}$

\section{Curved part \\ Electrode diameter : $15 \mathrm{~mm}$}

Machining stability was quite good and no short circuit occurred during machining. Machining result is shown in figure 7. Machining time for this tunnel was about 4 hours and it is easy to shorten machining time with more powerful electrical conditions. Figure 7 shows curved tunnel was dug smoothly and there is no step in the tunnel.

Usually when a deep hole is machined with EDM, machining stability is not good, because EDMed debris is stagnant in the hole. For example, stagnant debris induces discharge to already machined side area and the hole becomes concave, or these side area discharges disturb discharge to the direction of movement and machining speed becomes slow. However, in this experiment these phenomena did not occur. The reason of it can be thought as follows; the electrode is placed at the end of the apparatus and debris is easily removed from the area where discharge occurs even if it does not removed from the hole. 


\section{CONCLUSIONS}

In this paper, a new method to machine a curved tunnel was proposed. This system is composed of a curved electrode-drive part that has an electrode at the end of it and a guide to straighten the electrode-drive part. Machining test was done with the system, and conclusions are as follows;

(1) The system proposed in this report is simple and easy to control.

(2) Machining stability is good even when the curved area is machined.

(3) A smooth curved tunnel can be machined into the workpiece.

And future views are as follows; in this report, authors tried machining a curved hole. However, it was $15 \mathrm{~mm}$ in diameter and too large for a coolant tunnel. So we consider problem to be solved is machining a smaller curved tunnel into the workpiece with the same accuracy and machining stability. And application test must be done with a real mould to control temperature and check the effect of the curved coolant tunnel.

\section{BIBLIOGRAPHY}

1) Fukui, M., Kanoh, H., Kinoshita, N., " Development of Mole-EDM ", Electro-machining technology ( Denki-kakou-gijutsu ), 12, 38, 1-8, 1988 (in Japanese )

2) Fukui, M., Kinoshita, N., "Development a 'Mole' electric discharge digging machining", Annals of the CIRP, Vol.38(1), 203-206,1989

3) Goto, A., Fukui, M., Kinoshita, N., "Development of Mole-EDM", Journal of the Japan society of electrical-machining engineers, 25, 50, 23-31, 1991 (in Japanese )

4) Takeuchi, A., Watanabe, K., Goto, A., Magara, T., “ Machining of curved tunnel with Mole-EDM (1st report )", Die and mold technology ( Kata-gijutsu ), 12, 8, 100-101, 1997 (in Japanese )

5) Ichiyasu, S., Takeuchi, A., Watanabe, K., Goto, A., Magara, T. "Machining curved tunnel for coolant with mole EDM ", Proceedings of the 4th International Conference on Die and Mold Technology, 224230,1997

6) Goto, A., Takeuchi, A., Watanabe, K. “ Machining of curved tunnel with Mole-EDM", Die and mold technology ( Kata-gijutsu ), 15, 11, 46-49, 2000 (in Japanese )

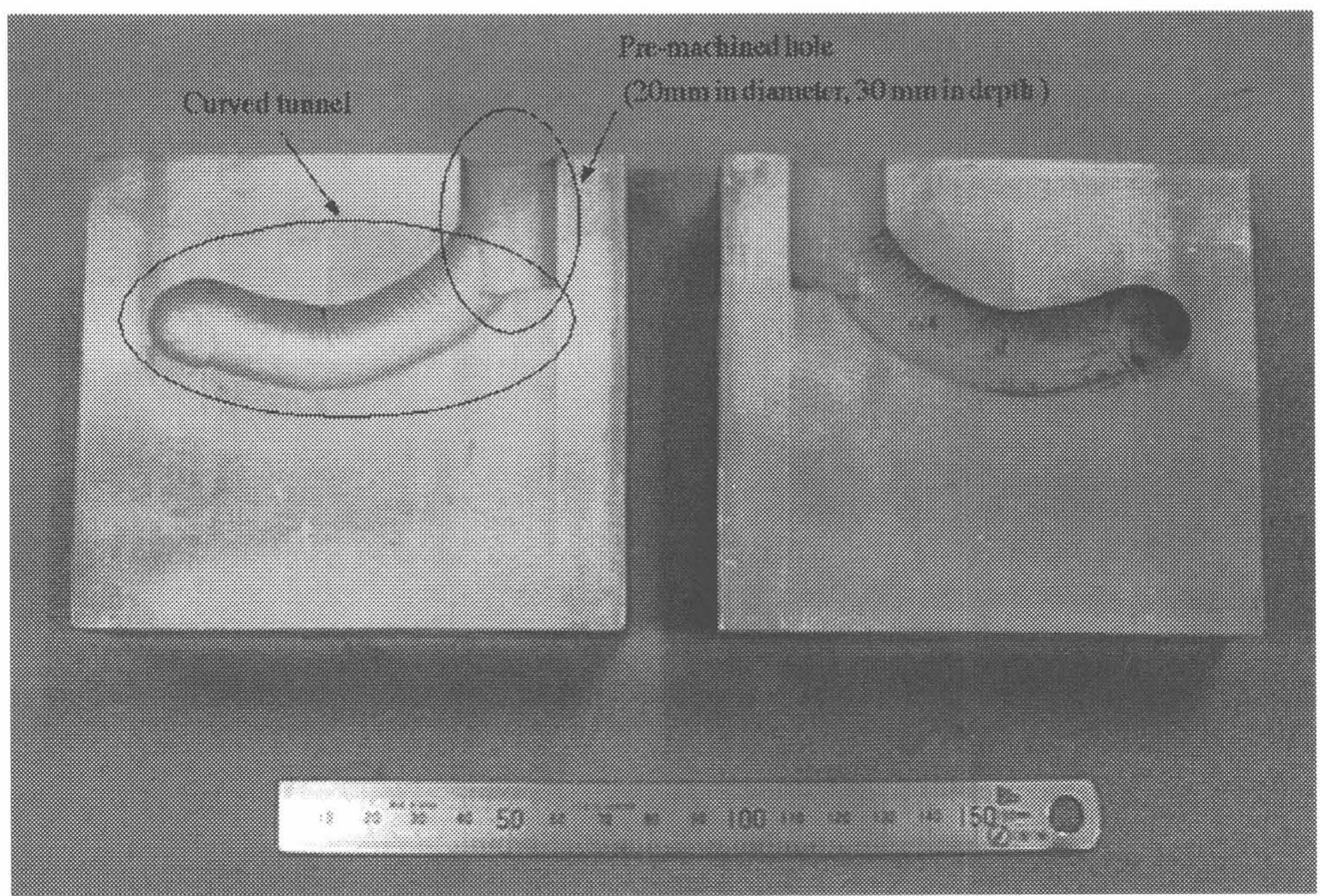

Figure 7 Example of curved tunnel 